\title{
Cholesterol 24S-Hydroxylase Overexpression Inhibits the Liver X Receptor (LXR) Pathway by Activating Small Guanosine Triphosphate-Binding Proteins (sGTPases) in Neuronal Cells
}

\author{
Miguel Moutinho • Maria João Nunes • Anita Q. Gomes • Maria João Gama • \\ Angel Cedazo-Minguez • Cecília M. P. Rodrigues • Ingemar Björkhem • Elsa Rodrigues
}

Received: 28 March 2014 / Accepted: 21 July 2014 / Published online: 2 August 2014

(C) Springer Science+Business Media New York 2014

\begin{abstract}
The neuronal-specific cholesterol 24S-hydroxylase (CYP46A1) is important for brain cholesterol elimination. Cyp46a1 null mice exhibit severe deficiencies in learning and hippocampal long-term potentiation, suggested to be caused by a decrease in isoprenoid intermediates of the mevalonate pathway. Conversely, transgenic mice overexpressing CYP46A1 show an improved cognitive function. These results raised the question of whether CYP46A1 expression can modulate the activity of proteins that are crucial for neuronal function, namely of isoprenylated small guanosine triphosphate-binding proteins (sGTPases). Our results
\end{abstract}

M. Moutinho $\cdot$ M. J. Nunes $\cdot$ M. J. Gama $\cdot$ C. M. P. Rodrigues

E. Rodrigues $(\triangle)$

Research Institute for Medicines (iMed.ULisboa), Faculty of Pharmacy, Universidade de Lisboa, Av. Prof. Gama Pinto, 1649-003 Lisbon, Portugal

e-mail: elsa.rodrigues@ff.ul.pt

\section{A. Q. Gomes}

Instituto de Medicina Molecular (IMM), Faculdade de Medicina,

Universidade de Lisboa, Avenida Professor Egas Moniz,

1649-028 Lisbon, Portugal

\section{A. Q. Gomes}

Escola Superior de Tecnologia da Saúde de Lisboa, Av. D. João II, Lote 4.69.01, Parque das Nações, 1990-096 Lisbon, Portugal

\section{A. Cedazo-Minguez}

Department of Neurobiology, Care Sciences and Society, Karolinska Institutet-Alzheimer's Disease Research Center, Novum, Stockholm, Sweden

\section{Björkhem}

Division of Clinical Chemistry, Department of Laboratory Medicine, Karolinska Institutet, Karolinska University Hospital, Huddinge, Sweden show that CYP46A1 overexpression in SH-SY5Y neuroblastoma cells and in primary cultures of rat cortical neurons leads to an increase in 3-hydroxy-3-methyl-glutaryl-CoA reductase activity and to an overall increase in membrane levels of RhoA, Rac1, Cdc42 and Rab8. This increase is accompanied by a specific increase in RhoA activation. Interestingly, treatment with lovastatin or a geranylgeranyltransferase-I inhibitor abolished the CYP46A1 effect. The CYP46A1-mediated increase in sGTPases membrane abundance was confirmed in vivo, in membrane fractions obtained from transgenic mice overexpressing this enzyme. Moreover, CYP46A1 overexpression leads to a decrease in the liver $\mathrm{X}$ receptor (LXR) transcriptional activity and in the mRNA levels of ATPbinding cassette transporter 1, sub-family $\mathrm{A}$, member 1 and apolipoprotein E. This effect was abolished by inhibition of prenylation or by co-transfection of a RhoA dominantnegative mutant. Our results suggest a novel regulatory axis in neurons; under conditions of membrane cholesterol reduction by increased CYP46A1 expression, neurons increase isoprenoid synthesis and sGTPase prenylation. This leads to a reduction in LXR activity, and consequently to a decrease in the expression of LXR target genes.

Keywords CYP46A1 · Cytochrome P450 · Brain metabolism $\cdot$ Cholesterol $\cdot$ Small GTPases $\cdot$ Isoprenoids . Prenylation $\cdot$ RhoA

\section{Introduction}

Cholesterol, apart from being an essential component of cellular membranes, is a key regulator of cellular processes in the central nervous system (CNS), playing a role in promoting 
neurite outgrowth [1-5], in synaptogenesis and synaptic integrity, and in neurotransmitter release [6-9]. In addition to the brain-specific activities, cholesterol synthesis generates intermediate products, such as isoprenoids and ubiquinone [10]. Therefore, constant levels of this sterol are required for normal brain functioning. Its homeostasis is maintained, in part, by an efficient blood-brain barrier that prevents exchanges with lipoprotein cholesterol from circulation. Thus to meet cholesterol needs, de novo and in situ synthesis occur in the CNS. The conversion of cholesterol into 24(S)-hydroxycholesterol (24OHC), by the neuronal-specific cytochrome P450 cholesterol 24S-hydroxylase (CYP46A1), has been described as the major cholesterol elimination mechanism [11-13]. In vitro, $24 \mathrm{OHC}$ has been shown to be a ligand for the liver X receptor (LXR) [14, 15]. Surprisingly, however, in transgenic mice overexpressing CYP46A1, activation of the LXR pathway was not observed, despite the higher levels of $24 \mathrm{OHC}$ [16]. In accordance to this, selective overexpression of CYP46A1, in the cortex and hippocampus of transgenic mice model for $\mathrm{AD}$, ameliorated the amyloid $\beta$ pathology, without activation of the LXR pathway [17]. Knockout mice lacking Cyp46a1 have a $\approx 40 \%$ reduction in brain cholesterol excretion, but this decrease is compensated for by a reduction in the de novo synthesis that maintains normal steady-state levels [13]. Cyp46a1 null mice exhibit severe deficiencies in spatial, associative and motor learning, and hippocampal long-term potentiation (LTP) $[18,19]$. Interestingly, these studies with knockout mice are consistent with the possibility that a decrease in cholesterol synthesis may limit the supply of isoprenoid intermediates of the mevalonate pathway, required for learning and synaptic plasticity. Accordingly, transgenic mice overexpressing CYP46A1 exhibit increased brain cholesterol synthesis, increased levels of synaptic proteins in the hippocampus, as well as improved memory function when compared to wild-type controls [16, 20].

These results have raised the question of whether CYP46A1 expression levels may alter the availability of isoprenoids intermediates, possibly affecting the amount of crucial isoprenylated proteins in neurons. Indeed, mevalonate, the product of 3-hydroxy-3-methyl-glutaryl-CoA reductase (HMGR), can be converted into farnesyl-diphosphate (FFP) and geranylgeranyl-diphosphate (GGPP) that, among other functions, can covalently bind to proteins, such as most small guanosine triphosphate-binding proteins (sGTPases), and act as anchors for membrane association. sGTPases comprise a superfamily of monomeric proteins classified into, at least, five families (Ras, Rho, Rab, Sar1/Arf, and Ran) that are involved in complex signaling networks and regulate diverse cellular activities. These activities include intracellular vesicle transport, cell adhesion, endocytosis, cytoskeletal organization, cell cycle progression, receptor signaling, vesicle trafficking, and gene expression [21, 22]. Membrane association and targeting, binding to regulators, and activation of downstream effectors are dependent on lipid posttranslational modifications for all sGTPases, except those from the Ran family [21]. Sar/Arf sGTPases undergo posttranslational myristoylation, while the Ras, Rho, and Rab families undergo a C-terminal prenylation. While Ras proteins are farnesylated [23, 24], Rho proteins are geranylgeranylated or farnesylated [25], and Rab proteins are mainly digeranylgeranylated but some can be monogeranylgeranylated $[26,27]$. Prenylated sGTPases cycle between a GDP (inactive)/GTP (active) binding conformation that combines with cytosol/membrane alternation, which is mediated by guanine dissociation inhibitors. These latter inhibitors form soluble complexes with sGTPases by binding their lipid moiety and are responsible for the extraction and delivery of sGTPases to membranes $[21,28]$.

Rho proteins have been extensively associated with actin cytoskeleton remodeling and are therefore critical to CNS neuronal cell migration, axon growth, guidance and branching, dendritic spine formation and stabilization, growth cone motility and collapse, and synapse formation [29-31]. Additionally, Rho GTPases have also been implicated in the correct formation of myelin sheaths [32]. Ras are involved in axon growth, memory formation, LTP induction and maintenance, and synaptic modulation [31, 33, 34], while Rab proteins have been mainly associated with endocytosis, synaptic vesicles exocytosis, axonal retrograde transport, and postsynaptic compartment dynamics of glutamate receptors [35]. In accordance to their pivotal role in the CNS, Ras, Rho, and Rab sGTPases have also been implicated in a number of neurological diseases. These diseases range from genetic defects such as X-linked non-specific mental retardation, Niemann-Pick disease Type $\mathrm{C}$ or choroideremia to sporadic neurological disorders such as late-onset AD, Parkinson's disease, multiple sclerosis, brain tumors, or even brain disorders resulting from ischemic stroke [10, 30, 36-42].

In the present work, evidence is presented that CYP46A1 expression levels are able to modulate isoprenoids synthesis and, ultimately, protein prenylation and activation of sGTPases. This modulation is shown to be important for activation of the LXR signaling system. Our results explain the surprising finding that this system is not activated in CYP46A1 transgenic mice in spite of high levels of the efficient LXR activator 24S-hydroxycholesterol [16].

\section{Materials and Methods}

Reagents and Antibodies

The following primary antibodies were used: anti-RhoA (clone 67B9, \#2177; Cell Signaling Technology, Beverly, MA, USA), anti-Rac1 (clone 23A8, \#05-389; Millipore, Temecula, CA, USA), anti-Rab8 (clone 4/Rab4, \#610844; BD 
Transduction Laboratories), anti-Cdc42 (clone B-8, sc-8401; Santa Cruz Biotechnology Inc., Santa Cruz, CA, USA), antiapolipoprotein E (APOE) (clone M-293, sc-98574; Santa Cruz), anti-glyceraldehyde 3-phosphate dehydrogenase (GAPDH) (clone 6C5, sc-32233; Santa Cruz), antiFLAG ${ }^{\circledR}$ M2 (clone M2, F1804; Sigma-Aldrich Inc., St Louis, MO, USA), anti-calnexin (ab7580; Abcam, Cambridge, UK), and anti-HA-Peroxidase (3F10) (\#12013819001, Roche Applied Science). The chemical inhibitors GGTi-2133 and lovastatin were purchased from Sigma and Pefabloc ${ }^{\circledR}$ from Roche.

\section{Cell Culture}

The SH-SY5Y human neuroblastoma cell line was cultured as previously described [43]. Briefly, cells were maintained in low glucose DMEM (Sigma), at $37{ }^{\circ} \mathrm{C}$ in humidified $5 \%$ $\mathrm{CO}_{2}$. The media was supplemented with $10 \%$ heat inactivated fetal bovine serum, $2 \mathrm{mML}$-glutamine, 100 units/mL penicillin, and $100 \mu \mathrm{g} / \mathrm{mL}$ streptomycin (Gibco ${ }^{\circledR}$, Invitrogen).

Primary cultures of rat cortical neurons were prepared from 17- to 18-day-old fetuses of Wistar rats as described previously [44] with minor modifications. In short, pregnant rats were sacrificed in a $\mathrm{CO}_{2}$ chamber and the fetuses were collected in Hank's balanced salt solution and rapidly decapitated. After removal of meninges and white matter, the brain cortex was collected in Hank's balanced salt solution without $\mathrm{Ca}^{2+}$ and $\mathrm{Mg}^{2+}$ (HBSS-2). The cortex was then mechanically fragmented, transferred to $0.05 \%$ trypsin, and incubated for $15 \mathrm{~min}$ at $37^{\circ} \mathrm{C}$. Following trypsinization, cells were washed twice in HBSS-2 containing $10 \%$ fetal bovine serum and resuspended in Neurobasal medium $\left(\mathrm{Gibco}^{\circledR}\right)$, supplemented with $0.5 \mathrm{mML}$-glutamine, $25 \mu \mathrm{M}$ L-glutamic acid, $2 \%$ B-27 supplement $\left(\mathrm{Gibco}^{\circledR}\right)$, and $12 \mathrm{mg} / \mathrm{mL}$ gentamicin. Isolated neurons were plated with a density around $640 / \mathrm{mm}^{2}$ on culture plates pre-coated with poly-D-lysine and maintained at $37^{\circ} \mathrm{C}$ in a humidified atmosphere of $5 \% \mathrm{CO}_{2}$. Half of the medium of the neuronal primary cultures was changed every 3-4 days until the 26th day in vitro (26DIV). Glutamic acid was only added into the medium when plating the cells. All the media changes and cell treatments afterwards were free from glutamic acid.

Preparation of Cytosolic and Membrane Fractions and Total Extracts from Cultured Cells

For the isolation of cytosolic and membrane fractions, cells were harvested in ice-cold cell wash buffer $(10 \mathrm{mM}$ Tris- $\mathrm{HCl}$, pH 7.4, $150 \mathrm{mM} \mathrm{NaCl}, 5 \mathrm{mM} \mathrm{MgCl} 2,1 \mathrm{mM}$ dithiothreitol [DTT], and $1 \mathrm{mM}$ of Pefabloc $\left.{ }^{\circledR}\right)$, and centrifuged at $1,000 \times \mathrm{g}$ for $10 \mathrm{~min}$ at $4{ }^{\circ} \mathrm{C}$. The pellet was resuspended in cell homogenisation buffer (10 mM Tris- $\mathrm{HCl}, \mathrm{pH} 7.5,1 \mathrm{mM}$ EDTA, $0.25 \mathrm{M}$ sucrose, $1 \mathrm{mM}$ DTT, $1 \times$ protease inhibitor cocktailRoche Diagnostics GmbH, Penzberg, Germany) and homogenized by 20 passages through a $23 \times$ gauge needle attached to a $1-\mathrm{mL}$ syringe. The homogenate was centrifuged at $10,000 \times g$ for $5 \mathrm{~min}$ and the post-nuclear supernatant obtained was subjected to ultra-centrifugation at $100,000 \times g$ for $1 \mathrm{~h}$ at $4{ }^{\circ} \mathrm{C}$. The supernatant (cytosolic fraction-S100) was collected and the pellet (membrane fraction-P100) was resuspended in homogenization buffer.

For the preparation of total cell extracts, cells were harvested in phosphate-buffered saline and resuspended in lysis buffer (50 mM Tris-HCl, pH 8.0, $150 \mathrm{mM} \mathrm{NaCl,} 1 \%$ Triton-X 100) containing $1 \mathrm{mM}$ DTT and $1 \times$ protease inhibitor mixture. After incubation at $4{ }^{\circ} \mathrm{C}$, for $30 \mathrm{~min}$, samples were sonicated four times for $4 \mathrm{~s}$ each, on ice, followed by centrifugation at $12,000 \times \mathrm{g}$ for $15 \mathrm{~min}$ at $4{ }^{\circ} \mathrm{C}$.

Protein concentration was determined by Bradford method and extracts were stored at $-80{ }^{\circ} \mathrm{C}$ until further use.

Preparation of Cytosolic and Membrane Fractions from Mice Brain Cortex

Brain cortex tissue was obtained from wild-type and homozygous HA-tagged CYP46A1 transgenic mice, previously described and characterized [20]. Heterozygous mice cross-bred with C57B16 mice [16] from the sixth generation were inbred for an additional three generations in order to obtain the homozygous mice [20]. To isolate the cytosolic and membrane fractions of brain cortex tissue, a slice was cut and placed in ice-cold tissue homogenization buffer $(250 \mathrm{mM}$ Sucrose, $100 \mathrm{mM}$ potassium phosphate $\mathrm{pH} 6.7,5 \mathrm{mM} \mathrm{MgCl}_{2}$, $1 \mathrm{mM}$ DTT, and $1 \times$ protease inhibitor mixture). The tissue was homogenized with a motor-driven Bio-vortexer (NO1083; Biospec Products, Bartlesville, OK, USA) and centrifuged at $3,500 \times \mathrm{g}$ for $10 \mathrm{~min}$ at $4{ }^{\circ} \mathrm{C}$. The resulting pellet, containing nuclei and cell debris, was discarded and the supernatant was further centrifuged at $100,000 \times \mathrm{g}$ for $30 \mathrm{~min}$ at $4{ }^{\circ} \mathrm{C}$. The supernatant (cytosolic fraction-S100) was collected and the pellet (membrane fraction-P100) was resuspended in homogenization buffer.

\section{Western Blot Analysis}

Proteins were subject to SDS-PAGE gels, electroblotted onto Immobilon P membrane (IPVH00010, Millipore), and incubated with specific antibodies. Results were quantified using the Quantity One version densitometry analysis software (Bio-Rad Laboratories Inc., Hercules, CA, USA).

\section{RhoA Activity Assay}

RhoA activity was measured in SH-SY5Y cells lysates using an ELISA-based RhoA activation assay Biochem Kit ${ }^{\mathrm{TM}}$ (GLISA $^{\mathrm{TM}}$, Cytoskeleton Inc., Denver, CO, USA), according to the manufacturer's instructions. Briefly, fresh cell lysates were added to the RhoA-GTP affinity plate that was coated with the 
Rhotekin-binding domain of RhoA for $30 \mathrm{~min}$. The lysates were incubated with primary and secondary antibodies for 45 min each. After adding the detection reagent, the luminescence was measured in GloMax ${ }^{\circledR}$-Multi Detection System (Promega, Madison, WI, USA).

\section{Expression Analysis}

Total cell RNA was extracted using Trizol Reagent (Invitrogen) following manufacturer's instructions. Real-time PCR (qPCR) analysis for HMGR and 3-hydroxy-3-methylglutaryl-coenzyme A synthase (HMGS), LDL receptor (LDLR), ATP-binding cassette transporter, sub-family A, member 1 (ABCA1), and APOE was performed using SYBR green Master Mix in an ABI 7300 sequence detection system (Applied Biosystems, Foster City, CA, USA) and specific primers (Table 1). Results presented were obtained from at least three individual experiments and each sample was assayed in triplicate. The mRNA levels of the genes of interest were normalized to the mRNA levels of $\beta$-actin and expressed as fold changes relative to controls, using the $\Delta \Delta \mathrm{Ct}$ method. Statistical analysis was performed with the $\Delta \mathrm{Ct}$ values.

\section{HMG-CoA Reductase Activity Levels}

HMGR activity was measured using the HMG-CoA Reductase Assay Kit (Sigma) following manufacturer's instructions. Briefly, the cells were harvested and subjected to a centrifugation of $500 \times \mathrm{g}, 5 \mathrm{~min}$ at $4{ }^{\circ} \mathrm{C}$. The pellet was resuspended in

Table 1 List of primers used for qPCR

\begin{tabular}{|c|c|c|}
\hline Gene & Species & Sequence $\left(5^{\prime}-3^{\prime}\right) /$ source \\
\hline \multirow[t]{2}{*}{ HMGR } & \multirow[t]{2}{*}{ Human } & 5' ATAGGAGGCTACAACGCCCAT 3' (fwd) \\
\hline & & 5' TTCTGTGCTGCATCCTGTCC 3'(rev) \\
\hline \multirow[t]{2}{*}{ HMGS } & \multirow[t]{2}{*}{ Human } & 5' GGCACAGCTGCTGTCTTCAAT 3' (fwd) \\
\hline & & 5' ACCAGGGCATACCGTCCAT 3' (rev) \\
\hline \multirow[t]{2}{*}{ LDLR } & \multirow[t]{2}{*}{ Human } & 5' CAGATATCATCAACGAAGC 3' (fwd) \\
\hline & & 5' CCTCTCACACCAGTTCACTCC 3' (rev) \\
\hline \multirow[t]{4}{*}{ APOE } & \multirow[t]{2}{*}{ Human } & 5' GACTGGCCAATCACAGGC 3' (fwd) \\
\hline & & 5' CTGTCTCCACCGCTTGCTC 3' (rev) \\
\hline & \multirow[t]{2}{*}{ Rat } & 5' CTTCTGGATTACCTGCGCT 3' (fwd) \\
\hline & & 5' GTCCTCCATCAGTACCGTCAG 3' (rev) \\
\hline \multirow[t]{4}{*}{ ABCA1 } & \multirow[t]{2}{*}{ Human } & 5' CCTGTTTCCGTTACCCGACTC 3' (fwd) \\
\hline & & 5' ACAGGCGAGCCACAATGG 3' (rev) \\
\hline & \multirow[t]{2}{*}{ Rat } & 5' CCCGGCGGAGTAGAAAGG 3' (fwd) \\
\hline & & 5' AGGGCGATGCAAACAAAGAC 3' (rev) \\
\hline \multirow[t]{4}{*}{$\beta-\operatorname{actin}$} & \multirow[t]{2}{*}{ Human } & 5' CTGGAACGGTGAAGGTGACA 3' (fwd) \\
\hline & & 5' AAGGGACTTCCTGTAACAATCCA 3' (rev) \\
\hline & \multirow[t]{2}{*}{ Rat } & 5' CTTGCAGCTCCTCCGTCGCC 3' (fwd) \\
\hline & & 5' CTTGCTCTGGGCCTCGTCGC 3' (rev) \\
\hline
\end{tabular}

$1 \times$ assay buffer and homogenized by 20 passages through a $25 \times$ gauge needle attached to a $2-\mathrm{mL}$ syringe. The cell extract was centrifuged again for $5 \mathrm{~min}, 500 \times \mathrm{g}$ at $4{ }^{\circ} \mathrm{C}$ and the supernatant containing the cellular content was collected. After protein content determination by the Bradford method, $150 \mu \mathrm{g}$ of cell extract were added to a reaction solution containing $400 \mu \mathrm{M}$ NADPH, $0.3 \mathrm{mg} / \mathrm{mL}$ HMGCR with or without $500 \mathrm{nM}$ pravastatin in a total volume of $200 \mu \mathrm{L}$ per well in a 96-well plate. The absorbance at $340 \mathrm{~nm}$ was subsequently measured every $30 \mathrm{~s}$ for $50 \mathrm{~min}$ in Infinite ${ }^{\circledR}$ M200 (Tecan, Männedorf, Switzerland). The decrease in absorbance represents the oxidation of NADPH mediated by HMGR. Each sample was assayed in duplicate. The results are expressed as nanomole of NADPH consumed per minute per milligram of protein.

\section{Gene Reporter Assay}

To minimize variations in transfection efficiency, replicates were transfected in single batch suspension with $\mathrm{X}$ tremeGENE HP (Roche), according to the manufacturer's instructions. Plates containing 150,000 cells were cotransfected with $0.5 \mu \mathrm{g}$ of the reporter plasmid, $0.1 \mu \mathrm{g}$ of each expression vector, together with $0.025 \mu \mathrm{g}$ of a $\beta$-galactosidase expression plasmid (pSV40- $\beta \mathrm{GAL}$ ). Cells were inoculated in 24-well plates and maintained for $48 \mathrm{~h}$. Cells were harvested and lysed in reporter lysis buffer (Promega). Cell extracts were assayed for luciferase and $\beta$-galactosidase activity ( $\beta$-Gal Reporter Gene Assay, Roche).

Total Cholesterol Levels

Total cholesterol was quantified using the Amplex ${ }^{\circledR}$ Red cholesterol assay kit (Invitrogen) according to the manufacturer's instructions. Cell membrane fractions were diluted 1:50 in $1 \times$ reaction buffer and $50 \mu \mathrm{L}$ was used to quantify cholesterol. Samples were placed in a 96-well plate and the reaction was initiated by adding $50 \mu \mathrm{L}$ of the Amplex ${ }^{\circledR}$ Red reagent/HRP/cholesterol oxidase/cholesterol esterase working solution to each well. The reactions were incubated for $30 \mathrm{~min}$ at $37^{\circ} \mathrm{C}$. Fluorescence measurements were performed in a GloMax ${ }^{\circledR}$-Multi Detection System (Promega). Each sample was assayed in triplicate. Cholesterol levels were normalized with total protein levels and expressed as microgram of cholesterol per milligram of protein.

\section{Statistics}

Statistical analysis was performed using the Student's $t$ test, Mann-Whitney test, the ANOVA one-way and ANOVA twoway tests followed by Tukey or Dunnet multiple comparisons test. All analysis was performed using the GraphPad Prism 
version 5.01 for Windows, GraphPad Software, La Jolla, California, USA, www.graphpad.com.

\section{Results}

Overexpression of CYP46A1 Increases sGTPases Prenylation and Activity

We have hypothesized that alterations in CYP46A1 expression levels may affect the availability of isoprenoid intermediates of the mevalonate pathway, thereby influencing the amount of crucial isoprenylated proteins in neuronal cells. Although it has been described that a decrease in cholesterol synthesis affects the supply of isoprenoids in Cyp46al knockout mice $[18,19]$, it is not known whether this decrease influences protein prenylation, which is a critical posttranslational modification for many signalling proteins, namely most sGTPases. Therefore, we started to investigate whether an increase in CYP46A1 expression affects prenylation and activity of members of the Rho and Rab families of sGTPases in two different cellular models, with distinct endogenous CYP46A1 expression levels. We have used primary cultures of rat cortical neurons maintained for 26DIV which express high levels of CYP46A1, and SH-SY5Y human neuroblastoma cells, where CYP46A1 mRNA can barely be detected [43].

Firstly, to determine if the recombinant CYP46A1 protein retains its catalytic activity, we have transfected SH-SY5Y cells and 26DIV neurons with an expression vector coding for the human CYP46A1 (pFLAG-hCYP46A1) for 48 and $24 \mathrm{~h}$, respectively. These time points were chosen based on a time course analysis of transient CYP46A1 protein expression levels (data not shown). As expected, CYP46A1 overexpression induced a significant decrease in membrane cholesterol content. Membrane cholesterol levels decrease by $60 \%$ in SH-SY5Y cells and by $30 \%$ in 26DIV neurons transfected with pFLAG-hCYP46A1 as compared to cells transfected with empty vector (pFLAG) (Fig. 1).

Prenylation is an essential modification for membrane anchoring of sGTPases. Hence, membrane association of sGTPases provides a sensitive measure of their prenylation status [23]. Therefore, we have isolated membrane and cytosolic fractions of SH-SY5Y cells and 26DIV neurons, and the content of RhoA, Rac1, Cdc42, and Rab8 was determined by immunoblotting.

Our results show an overall significant increase in membrane association of all sGTPases tested after CYP46A1 overexpression in SH-SY5Y cells and 26DIV neurons (Fig. 2). In fact, we observed an increase of about 35, 53, 63, and $130 \%$ in the membrane levels of RhoA, Rac1, Cdc42, and Rab 8, respectively, in SH-SY5Y cells transfected for $48 \mathrm{~h}$ with
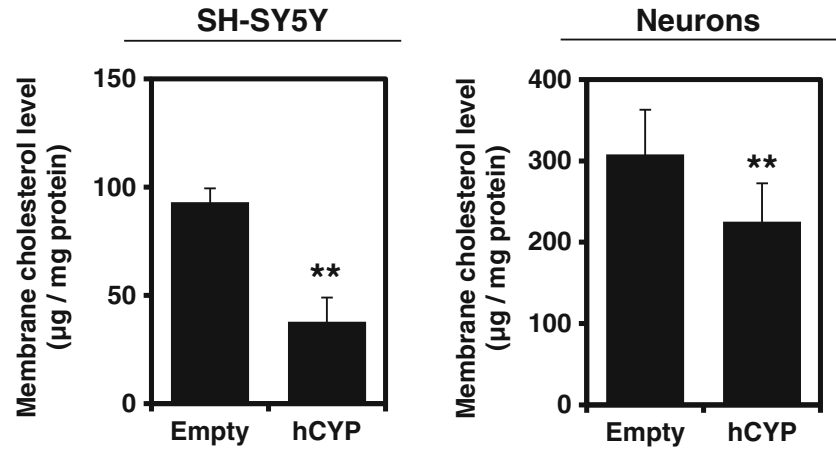

Fig. 1 CYP46A1 overexpression reduces cholesterol content in the membrane fraction of SH-SY5Y and 26DIV neurons. Membrane cholesterol levels were determined with the Amplex ${ }^{\circledR}$ Red cholesterol determination kit in the membrane fraction isolated from SH-SY5Y cells and in 26DIV neurons transfected with empty pFLAG (Empty) or pFLAGhCYP46A1 (hCYP) for 48 and $24 \mathrm{~h}$, respectively. Data represents mean values \pm SEM from at least three independent experiments and is expressed as microgram of membrane cholesterol per milligram of membrane protein $(* * p<0.01)$

pFLAG-hCYP46A1, as compared to cells transfected with empty vector (Fig. 2a). Concomitantly, we could observe a significant decrease of about 50,30, 25, and $20 \%$ in the cytosolic levels of RhoA, Rac1, Cdc42, and Rab 8, respectively (Fig. 2b). These results were further confirmed in 26DIV neurons transfected with pFLAG-hCYP46A1 for $24 \mathrm{~h}$, where we could also observe a significant increase of approximately $65,26,21$, and $97 \%$ in the membrane levels of RhoA, Rac1, Cdc42, and Rab 8, respectively (Fig. 2c) and a concomitant decrease of about $5 \%$ in RhoA and Rac1, and 15 and $25 \%$ in $\mathrm{Cdc} 42$ and Rab8, respectively in the cytosolic fraction (Fig. 2d). Importantly, this CYP46A1-dependent increase of membrane-associated sGTPases is not due to an increase in their abundance as the analysis of total cell protein extracts by immunoblotting shows that the total protein levels of the tested sGTPases remain unchanged after overexpression of hCYP46A1 both in neuroblastoma cells and in 26DIV neurons (data not shown).

Overall, these results clearly demonstrate the effective translocation of RhoA, Rac1, Cdc42, and Rab8 from the cytosol to membranes induced by increased CYP46A1 expression.

To assess if the CYP46A1-dependent increase in the membrane association of sGTPases is dependent on the cellular isoprenoid pool, we treated cells with lovastatin, an inhibitor of HMGR, the enzyme responsible for the rate-limiting step for cholesterol and isoprenoid production. Since lovastatin affects membrane association of sGTPases of both Rho and Rab families, and once we had observed a higher increase in Rab8 membrane content, we have chosen to determine the effect of lovastatin treatment in the CYP46A1-dependent increase in membrane association of this sGTPase. SHSY5Y cells were transfected with pFLAG-hCYP46A1 or with empty vector and, $24 \mathrm{~h}$ afterwards, were treated with vehicle 
A

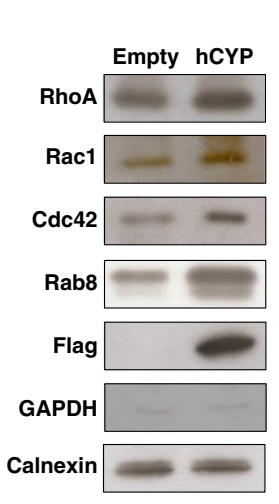

SH-SY5Y membrane fraction
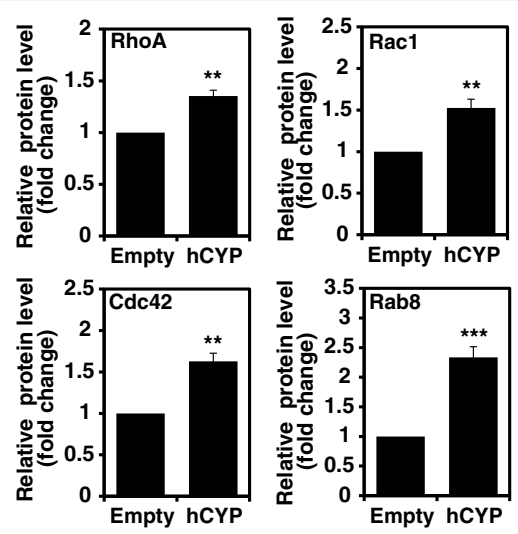

C
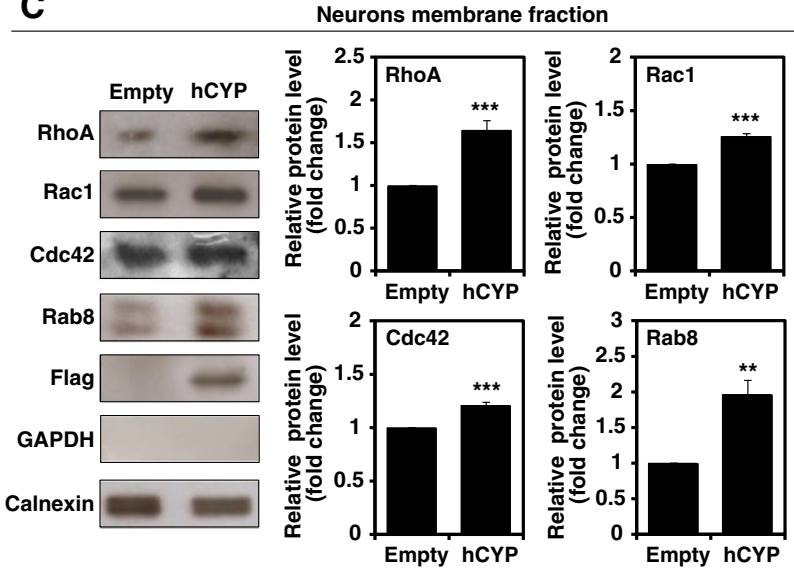

Fig. 2 CYP46A1 overexpression in human SH-SY5Y cells and 26DIV neurons increases sGTPases membrane association. Western blot analysis of sGTPases content in membrane (a and $\mathbf{c}$ ) and cytosolic (b and d) fractions, 48 and $24 \mathrm{~h}$ after transfection of SH-SY5Y cells and 26DIV neurons, respectively, with empty pFLAG (Empty) or with pFLAGhCYP46A1 $(h C Y P)$. GAPDH and calnexin levels were used as loading

or with $20 \mu \mathrm{M}$ lovastatin for another $24 \mathrm{~h}$. Not only lovastatin treatment decreased the amount of membrane-associated Rab8 by $60 \%$ in cells transfected with the empty vector but, more interestingly, it completely abolished the increase in Rab8 membrane content induced by CYP46A1 overexpression (two-way ANOVA $p<0.001$, Tukey HSD post hoc test) (Fig. 3).

To further confirm that the increase in CYP46A1 expression correlates with an increase in protein prenylation, we also determined the effect of geranygeranyl transferase inhibition on the CYP46A1-dependent sGTPase membrane association. GGTase-I recognizes protein substrates that have a consensus sequence termed "CAAX box" located at the carboxy terminus, and therefore target proteins of the Rho family. In contrast, proteins of the Rab family undergo two geranylgeranylation reactions and are almost exclusively the substrates for GGTase-II. Nevertheless, it has been shown that some members of the Rab family, such as Rab8, can also be prenylated by GGTase-I $[27,26]$. Therefore, we transfected
B SH-SY5Y cytosolic fraction
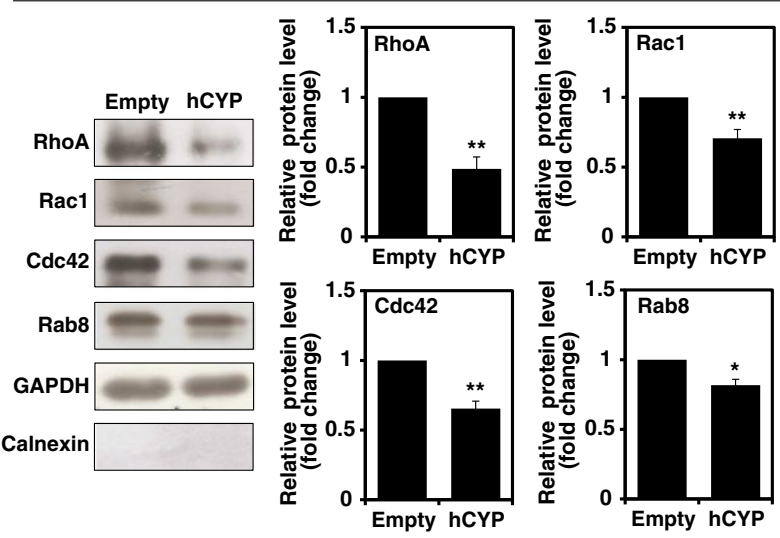

D

Neurons cytosolic fraction
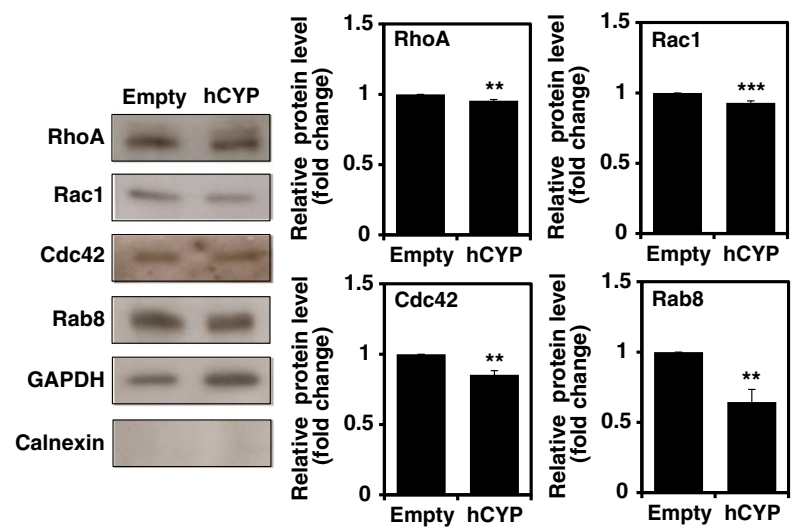

control for cytosolic and membrane fractions, respectively. The blots shown are representative of those obtain in at least three independent experiments. Data is represented as mean values \pm SEM of at least three experiments and is expressed as fold change relative to control $\left({ }^{*} p<0.05\right.$, $* * p<0.01, * * * p<0.001)$

SH-SY5Y cells with pFLAG-hCYP46A1 or with empty vector and after $24 \mathrm{~h}$ cells were treated with either vehicle or $50 \mathrm{nM}$ GGTi-2133, a GGTase-I inhibitor, for further $24 \mathrm{~h}$. Finally, the effect on the membrane content of one of the members of the Rho family, RhoA, and on Rab8 was analyzed by immunoblotting. Our results show that GGTi-2133 treatment, as expected, slightly decreases RhoA (15\%), but not Rab8 basal membrane association, while it clearly inhibits the CYP46A1-dependent increase in RhoA (two-way ANOVA $p<0.001$; Tukey HSD post hoc) and Rab8 (two-way ANOVA $p<0.001$; Tukey HSD post hoc test) (Fig. 4).

These results highlight that compounds that either decrease the cellular isoprenoid pool or inhibit geranylgeranylation reactions abolish the increased membrane association of sGTPases upon CYP46A1 overexpression, indicating that the observed differences are due to sGTPase prenylation.

Moreover, we also wanted to evaluate if this increase in sGTPases prenylation was reflected in an increased activation. Therefore, we used a G-LISA kit assay to evaluate RhoA 

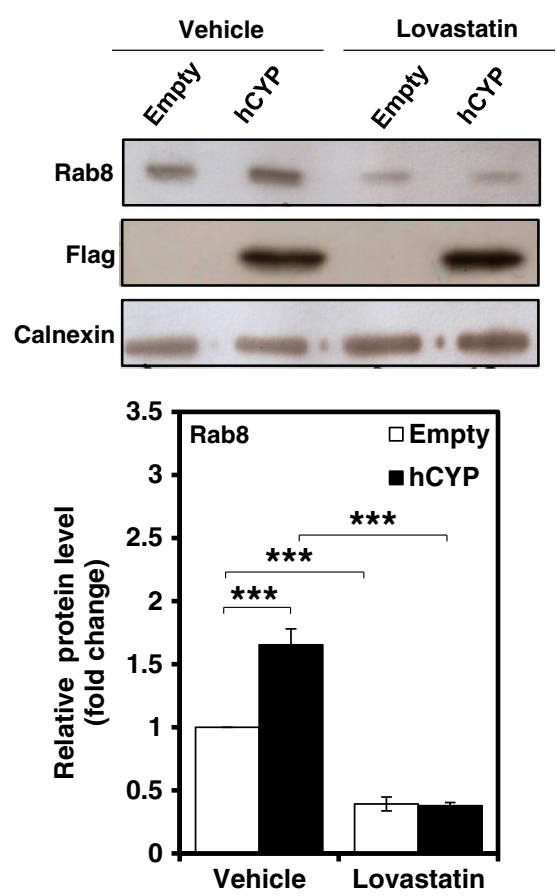

Fig. 3 Lovastatin abolishes the effect of CYP46A1 overexpression on sGTPases membrane association in human SH-SY5Y cells. Western blot analysis of Rab8 content in the membrane fraction isolated from SHSY5Y cells transfected with empty vector (Empty) or pFLAGhCYP46A1 $(h C Y P)$ for $24 \mathrm{~h}$ and treated for further $24 \mathrm{~h}$ with $20 \mu \mathrm{M}$ lovastatin or vehicle. Calnexin was used as loading control. The blots shown are representative of those obtain in at least three independent experiments. Data is represented as mean values $\pm \mathrm{SEM}$ and is expressed as fold change relative to control $(* * * p<0.001)$

activity in cell extracts from SH-SY5Y transfected for $24 \mathrm{~h}$ with pFLAG-hCYP46A1 or with empty vector and treated with vehicle or $50 \mathrm{nM}$ GGTi-2133 for further $24 \mathrm{~h}$ after transfection. Our results show that CYP46A1 significantly increases GTP-bound RhoA by approximately $50 \%$, which reflects an increase in RhoA activation status. GGTi-2133 treatment completely abrogates the CYP46A1 effect (twoway ANOVA $p<0.05$, Tukey HSD post hoc test) (Fig. 5).

Since CYP46A1 effect seems to be dependent on the supply of isoprenoids, we decided to assess how CYP46A1 overexpression affects the mevalonate pathway, by measuring HMGR activity $48 \mathrm{~h}$ after transfection of SH-SY5Y with pFLAG-hCYP46A1 or with empty vector (Fig. 6). The addition of $500 \mu \mathrm{M}$ pravastatin to non-transfected SH-SY5Y cell homogenates resulted in a $70 \%$ reduction of the basal NADPH consumption, while in the homogenates of cells that were serum starved for $24 \mathrm{~h}$, the NADPH consumption doubled when compared to control $(0.47 \pm 0.18 \mathrm{nmol} \mathrm{NADPH} /$ $\mathrm{min} / \mathrm{mg}$ protein) (ANOVA $p<0.001, F=16.62$, Tukey HSD post hoc test) (Fig. 6a). These data suggested that the NADPH consumption in these homogenates was specifically due to HMGR activity. Interestingly, overexpression of CYP46A1 induces a 2.3-fold significant increase in the rate of NADPH oxidation that is abolished by pravastatin addition, further confirming that this effect is due to an increase in HMGR activity (ANOVA $p<0.05, F=5.305$, Tukey HSD post hoc test) (Fig. 6b).

These results are in agreement with the significant increase in the levels of several cholesterol precursors that were previously described in the brains of transgenic mice overexpressing HA-CYP46A1 (C46-HA mice) [16]. To further confirm our observations, we isolated membrane and cytosolic fraction from the brain cortex of C46-HA mice and determined by immunoblotting the content of RhoA, Rac1, Cdc42, and Rab8 in both fractions. We observed an increase in membrane association of RhoA, Rac1, and Rab8 in C46-HA mice relative to wt controls that was similar to what was shown in cultured cells (Fig. 7). The membrane-associated level of RhoA, Rac1, and Rab8 increased by approximately 48, 89, and $18 \%$, respectively, and this was accompanied by a concomitant decrease in the abundance of sGTPases in the cytosol by 37,34 , and $44 \%$ relative to wt controls. However, in the
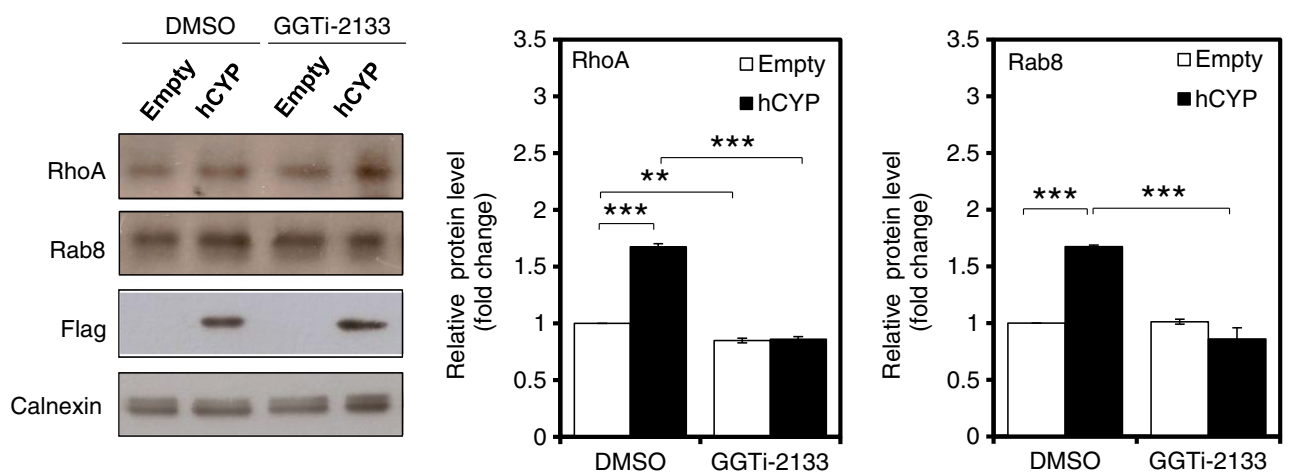

Fig. 4 GGTi-2133 abolishes the effect of CYP46A1 overexpression on sGTPases membrane association in human SH-SY5Y cells. Western blot analysis of RhoA and Rab8 content in membrane fraction in SH-SY5Y cells transfected with empty vector (Empty) or pFLAG-hCYP46A1 $(h C Y P)$ for $24 \mathrm{~h}$ and treated for further $24 \mathrm{~h}$ with $50 \mathrm{nM}$ GGTi-2133 or

vehicle. Calnexin was used as loading control. The blots shown are representative of those obtain in at least three independent experiments. Data is represented as mean values $\pm \mathrm{SEM}$ and is expressed as fold change relative to control $(* * p<0.01, * * * p<0.001)$ 


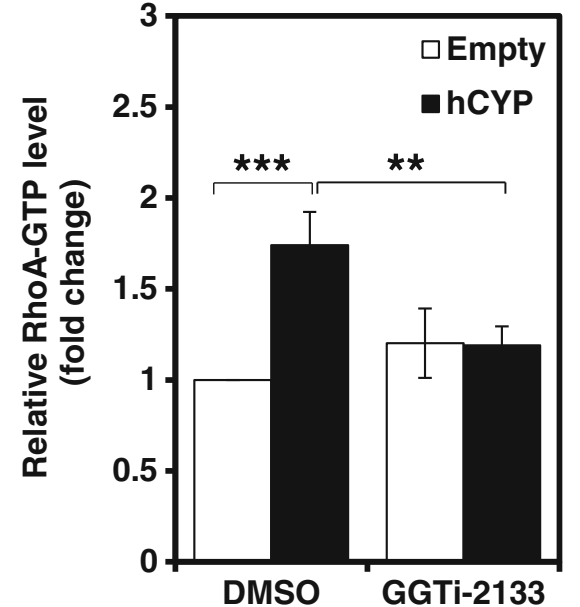

Fig. 5 GGTi-2133 abolishes the effect of CYP46A1 overexpression on RhoA activation status in human SH-SY5Y cells. G-LISA analysis of RhoA-GTP levels in SH-SY5Y cells transfected with empty vector (Empty) or pFLAG-hCYP46A1 $(h C Y P)$ for $24 \mathrm{~h}$ and treated for further $24 \mathrm{~h}$ with $50 \mathrm{nM}$ GGTi-2133 or vehicle. Data is represented as mean values \pm SEM of at least three independent experiments and is expressed as fold change relative to control $(* * p<0.01)$

case of Cdc 42 , there was a reduction of approximately $50 \%$ in both membrane and cytosolic fractions, which indicates a reduction of $\mathrm{Cdc} 42$ expression in these mice. When the values of membrane-associated $\mathrm{Cdc} 42$ are normalized to the total pool of membrane and cytosolic $\mathrm{Cdc} 42$, there is no statistical significant change between transgenic and wild-type mice (data not shown).

A

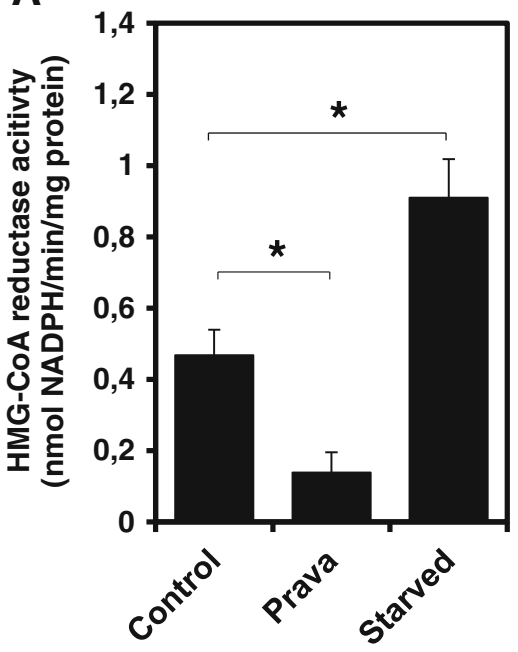

Fig. 6 Overexpression of CYP46A1 in human SH-SY5Y cells increases HMGR activity. HMGR specific activity measured by NADPH consumption was determined in SH-SY5Y cell homogenates. a Homogenates prepared from control cells, from $24 \mathrm{~h}$ serum-starved cells (Starved) or prepared from control cells with addition of $500 \mu \mathrm{M}$ pravastatin (Prava). b Homogenates prepared from cells transfected with empty
All together, these results show that CYP46A1 overexpression activates the mevalonate pathway and increases sGTPases prenylation and activation.

\section{4(S)-Hydroxycholesterol, in Contrast to CYP46A1}

Overexpression, Reduces RhoA Membrane Association

$24 \mathrm{OHC}$ is the endogenous product of cholesterol oxidation mediated by CYP46A1, therefore to assess if the observed changes in sGTPases induced by CYP46A1 overexpression were due to an increased production of this oxysterol, 26DIV neurons were incubated with $10 \mu \mathrm{M} 24 \mathrm{OHC}$ for $24 \mathrm{~h}$. Since, in vitro, $24 \mathrm{OHC}$ activates $\mathrm{LXR}$, in parallel experiments we incubated cells with $10 \mu \mathrm{M}$ TO901317, an LXR synthetic agonist. Total extracts and membrane fractions were obtained as previously described and the sGTPases content was assessed by Western blot. We observed that both $24 \mathrm{OHC}$ and TO901317 had similar effects, but neither recapitulated the overall increase in membrane-associated sGTPases induced by overexpression of CYP46A1. Indeed, although both LXR agonists induced a significant 40 to $50 \%$ increase of Rac1, Rab8, and Cdc42 content in the membrane fraction (Fig. 8), RhoA content in the membrane fraction was reduced by about 35 and $20 \%$ with $24 \mathrm{OHC}$ and TO901317, respectively (one-way ANOVA $p<0.001, F=18.97 ; p<0.01, F=$ $17.37 ; p<0.01, F=8.316$; and $p<0.01, F=10.78$, corresponding to RhoA, Rac1, Cdc42, and Rab8 analysis, respectively, Dunnet post hoc test) (Fig. 8). These results indicate that CYP46A1 overexpression and $24 \mathrm{OHC}$ have similar effects

B

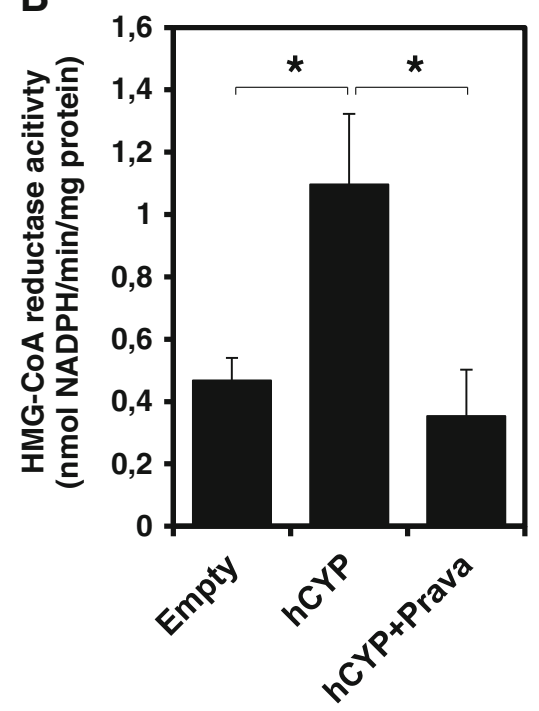

vector (Empty) or pFLAGhCYP46A1 $(h C Y P)$ for $48 \mathrm{~h}$ with and without the addition of $500 \mu \mathrm{M}$ pravastatin (Prava). Data is represented as mean values $\pm \mathrm{SEM}$ of at least three independent experiments and is expressed as nanomole of NADPH consumption per minute per milligram of protein $(\mathrm{nmol} / \mathrm{min} / \mathrm{mg})\left({ }^{*} p<0.05\right)$ 

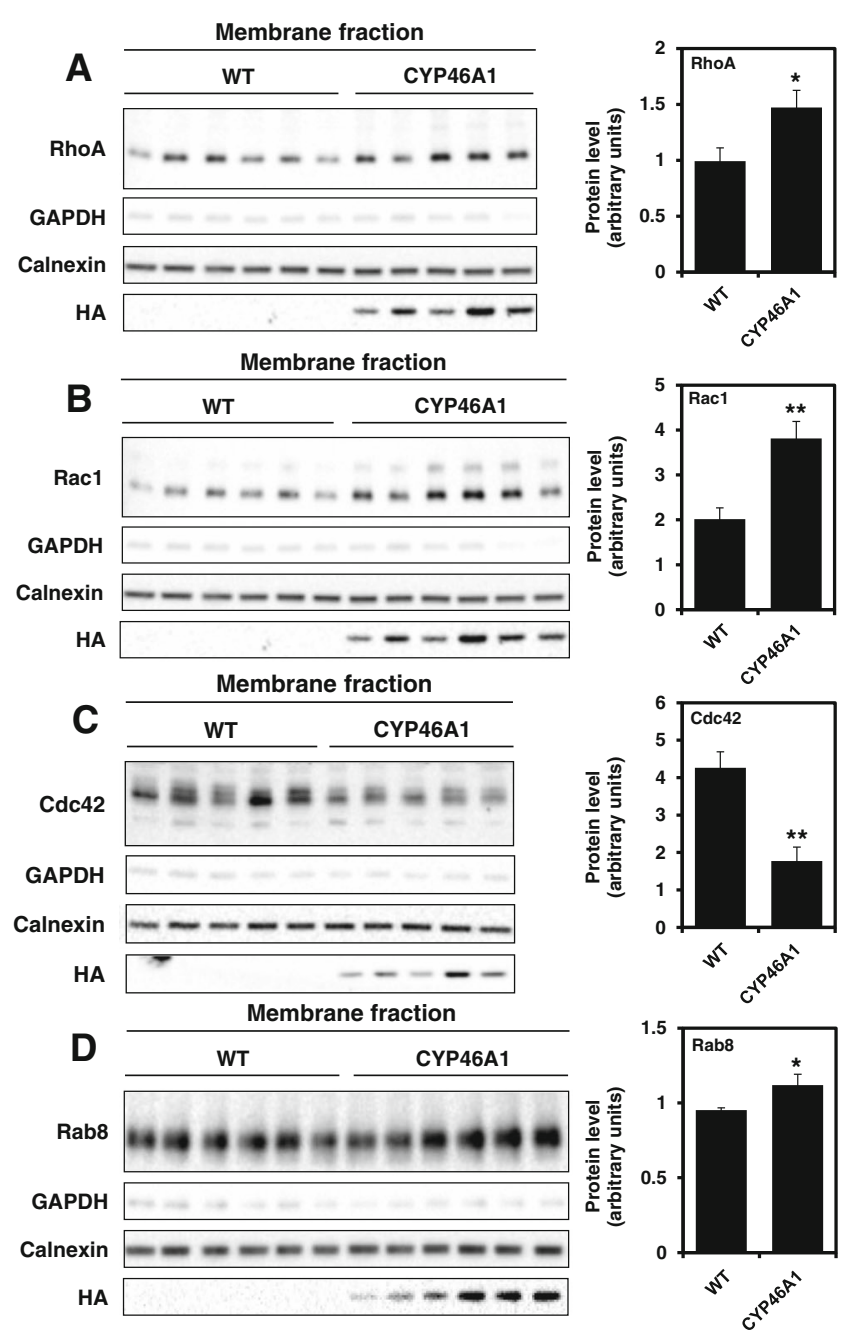

Fig. 7 Brain cortex of C46-HA mice present an increase in sGTPases membrane association. Western blot analysis of sGTPases content in membrane and cytosolic fractions (a-d) of C46-HA mice brain cortex. $G A P D H$ and calnexin levels were used as loading control for cytosolic

for Rac1, Cdc42, and Rab8 but opposite roles concerning RhoA membrane association.

CYP46A1 Overexpression Inhibits the LXR Pathway as a Consequence of RhoA Activation

As previously mentioned, inactivation of Cyp $46 a 1$ has been associated with a selective reduction of cholesterol synthesis [13], while a significant increase in the levels of several cholesterol precursors was observed in the brain of CYP46A1 transgenic mice $[16,20]$. Moreover, herein we have also observed an increase in HMGR activity in CYP46A1 transfected cells. Taken together, these findings suggest a close relationship between synthesis and catabolism of cholesterol in the brain. Therefore, we have determined by qPCR the mRNA levels of key genes involved in cholesterol homeostasis, namely HMGS and HMGR (synthesis), LDLR (uptake), ABCA1, and APOE (efflux) in SH-SY5Y cells
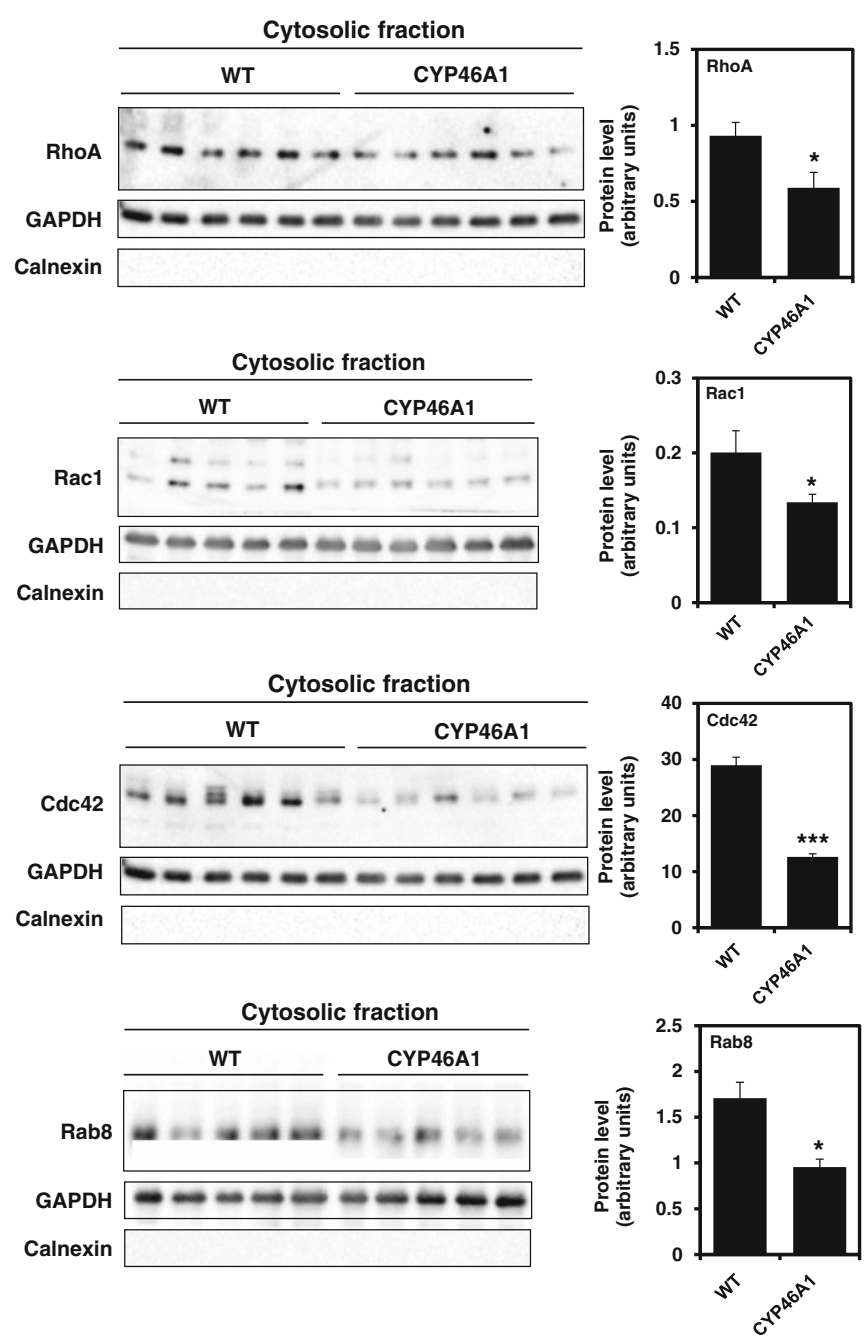

and membrane fractions, respectively. Data is represented as mean values \pm SEM and is expressed as arbitrary units $(* p<0.05, * * p<0.01$, $* * * p<0.001$ )

transfected with hCYP46A1. Although we had previously observed an increase in HMGR activity, our results show that HMGS and HMGR mRNA levels remain unchanged after CYP46A1 overexpression (Fig. 9a) which is consistent with the gene expression profile reported for C46-HA mice [20]. On the other hand, the mRNA levels of the LXR target genes, ABCA1 and APOE, were significantly down-regulated by approximately 30 and $20 \%$, respectively. To further confirm the CYP46A1 effect, we also transfected N26DIV neurons with pFLAG-hCYP46A1 and observed similar reductions of ABCA1 and APOE mRNA levels about 15 and $20 \%$, respectively (Fig. 9b). Furthermore, this decrease is not underlined by a reduction in $\operatorname{LXR} \alpha$ and $\mathrm{LXR} \beta$ expression, since their mRNA levels remain unchanged after CYP46A1 overexpression (data not shown). It was initially hypothesized that an increase in CYP46A1 expression would lead to increased levels of $24 \mathrm{OHC}$ and to a general activation of LXR and LXR-targeted genes in the brain. However, the observed 
Fig. 8 24OHC and TO901317 affect sGTPases membrane association in 26DIV neurons. Western blot analysis of sGTPases content in the membrane fraction of 26DIV neurons incubated with $10 \mu \mathrm{M}$ 24OHC or TO901317 for $24 \mathrm{~h}$. Values were normalized to the internal standard calnexin. Data is represented as mean values \pm SEM of at least three independent experiments and is expressed as fold change relative to control $\left({ }^{*} p<0.05,{ }^{* *} p<0.01\right.$, $* * * p<0.001)$

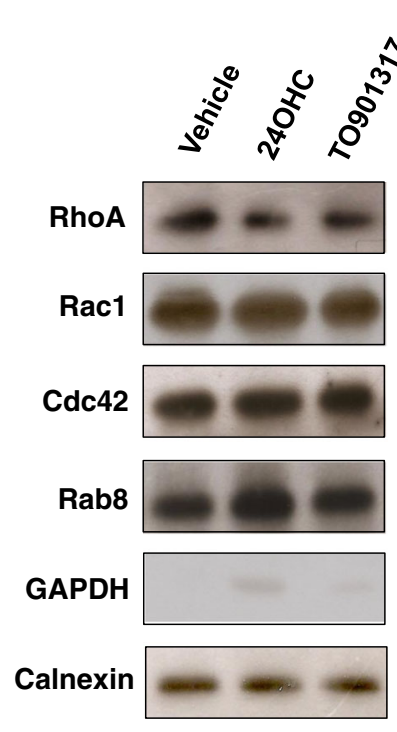

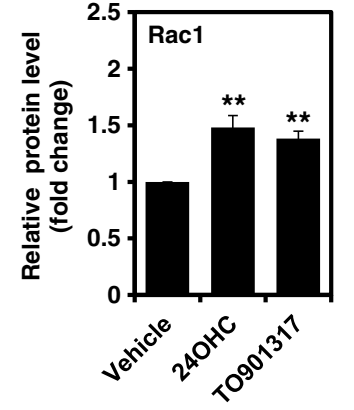
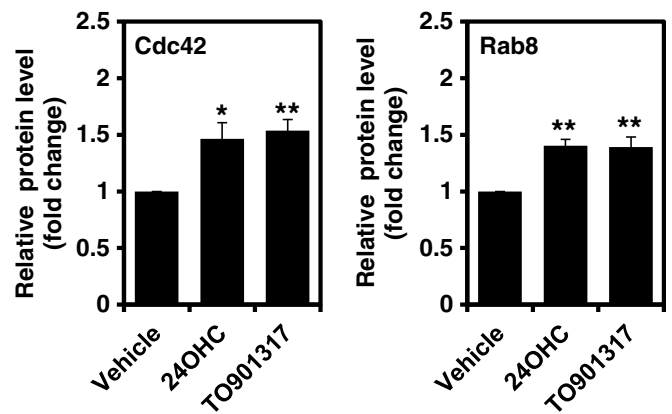

down-regulation of ABCA1 and APOE after CYP46A1 overexpression did not corroborate this hypothesis. Moreover, recent results from Shaffati and collaborators [16], obtained with the transgenic C46-HA mice, also showed that higher
Fig. 9 CYP46A1 overexpression reduces $\mathrm{ABCA} 1$ and $\mathrm{APOE}$ mRNA levels. a qPCR analysis of HMGS, HMGR, LDLR,

ABCA1, and APOE mRNA levels in SH-SY5Y cells transfected with empty vector (Empty) or pFLAG-hCYP46A1 $(h C Y P$ ) for $48 \mathrm{~h}$. b qPCR analysis of ABCA1 and APOE mRNA levels in 26DIV neurons transfected with Empty or hCYP for $24 \mathrm{~h}$. Values were normalized to the internal standard $\beta$-actin. Data is represented as mean values \pm SEM of at least three independent experiments and is expressed as fold change relative to control $\left({ }^{*} p<0.05\right)$
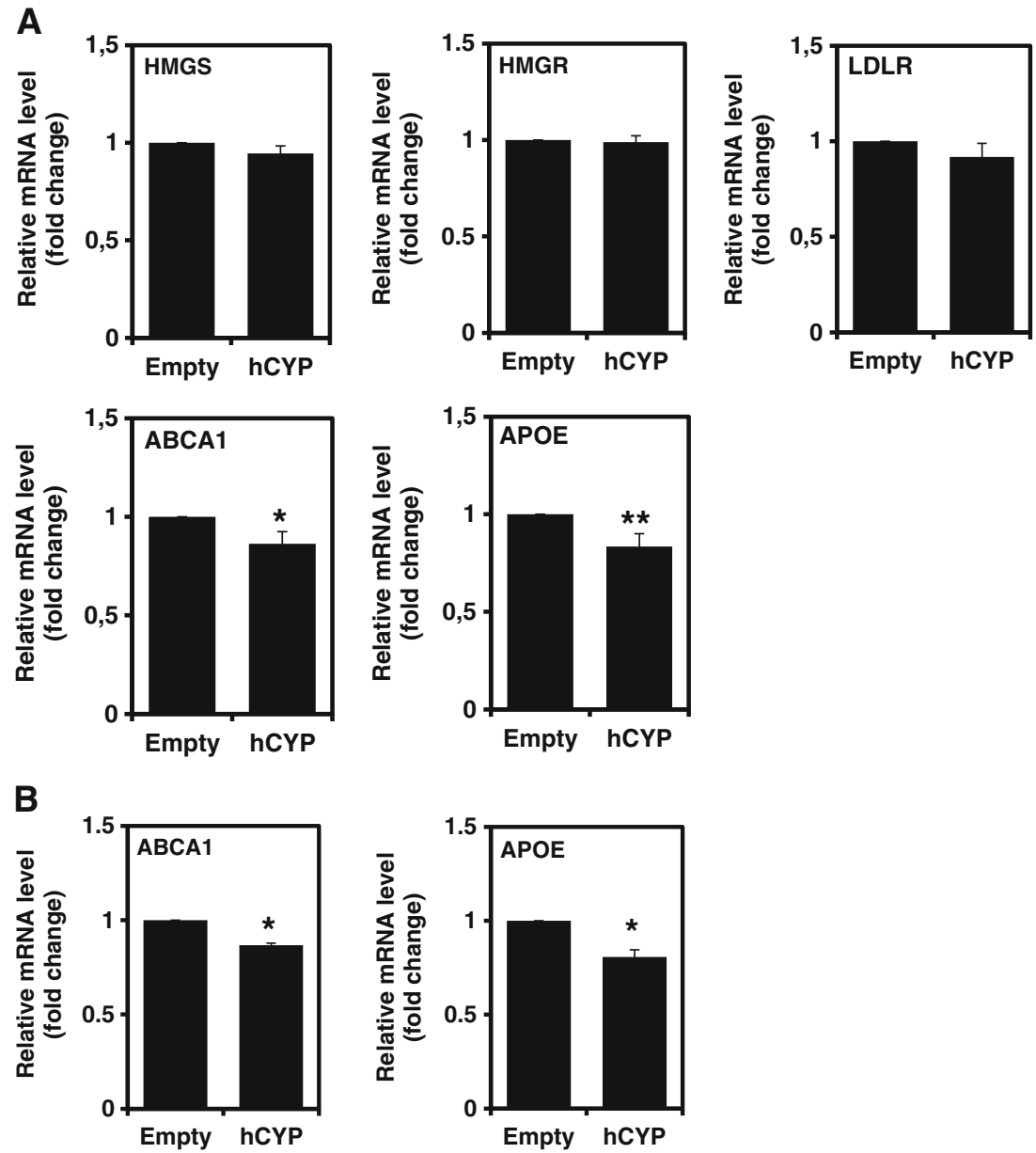
levels 24OHC due to CYP46A1 overexpression were not sufficient to drive LXR activation in vivo.

In order to compare the effect of CYP46A1 overexpression with $24 \mathrm{OHC}$ treatment, we have treated 26DIV neurons with $24 \mathrm{OHC}$ and determined the mRNA levels of LXR target genes. Our results show that incubation of $10 \mu \mathrm{M} 24 \mathrm{OHC}$ increases ABCA1 and APOE mRNA levels by five and twofold, respectively, which is the opposite effect of CYP46A1 overexpression (one-way ANOVA $p<0.001, F=$ $8.536 ; p<0.05, F=5.577$ for ABCA1 and APOE, respectively, Dunnet post hoc test) (Fig. 10).

Since activation of Rho GTPases has been associated with an inhibition of the LXR pathway [45-49] and we have observed that CYP46A1 overexpression and $24 \mathrm{OHC}$ treatment differentially affect RhoA membrane levels, we hypothesize that CYP46A1-dependent decrease in LXR target genes was dependent on the increase in RhoA prenylation. To test our hypothesis, we incubated cells transfected with pFLAGhCYP46A1 in the presence or absence of GGTi-2133 and observed that inhibition of prenylation abolished the CYP46A1-dependent decrease in ABCA1 and APOE mRNA levels (Fig. 11a). Moreover, we observed that co-transfection of a dominant-negative form of RhoA (pEGFP-RhoA N19) also leads to the loss of the CYP46A1 effect (Fig. 11b). To further confirm that CYP46A1 overexpression affects LXR activation, we performed a reporter gene assay in SH-SY5Y cells co-transfected with the luciferase reporter plasmids LXRE-ABCA1 or LXRE mut-ABCA1 and with empty vector or pFLAG-hCYP46A1 for $48 \mathrm{~h}$ (Fig. 12). Upon CYP46A1 overexpression, we observed a $40 \%$ decrease in luciferase activity in cells transfected with the LXRE-ABCA1 luciferase reporter plasmid, an effect that was not observed in cells
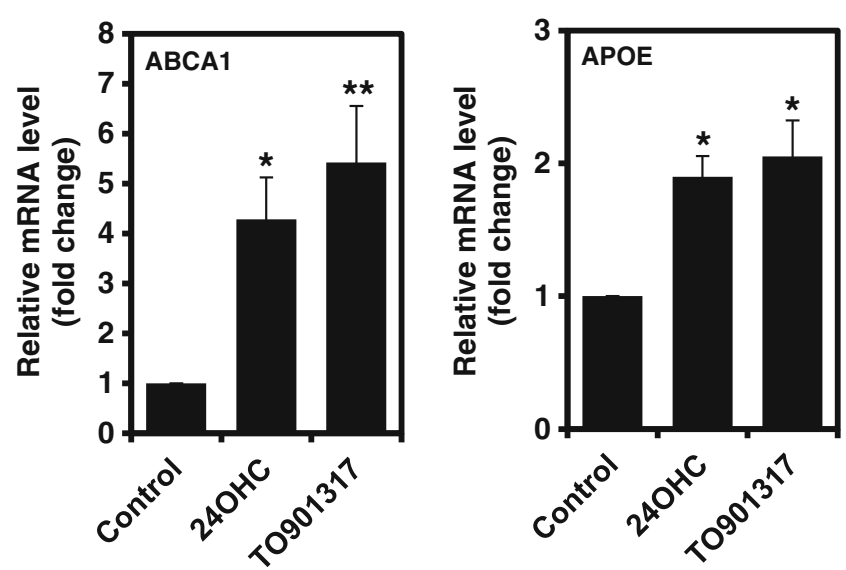

Fig. $1024 \mathrm{OHC}$ and TO901317 increases ABCA1 and APOE mRNA levels in 26DIV neurons. qPCR analysis of ABCA1 and APOE mRNA levels in 26DIV neurons incubated with $10 \mu \mathrm{M} 24 \mathrm{OHC}$ or TO901317 for $24 \mathrm{~h}$. Values were normalized to the internal standard $\beta$-actin. Data is represented as mean values \pm SEM of at least three independent experiments and is expressed as fold change relative to control $\left(^{*} p<0.05\right.$, $* * p<0.01$ ) transfected with the LXRE mut-ABCA1 luciferase reporter plasmid (Fig. 12a). In addition, we have co-transfected the pEGFP-RhoA N19 or the pEGFP empty vector with the luciferase reporter plasmids, and we observed that the CYP46A1-dependent decrease in LXR transcriptional activity was rescued by the inhibition of RhoA activity (Fig. 12b).

These results indicate that overexpression of CYP46A1 can effectively activate sGTPases signaling cascades and have a downstream impact in neuronal cells, namely the downregulation of the LXR pathway mediated by RhoA.

\section{Discussion}

The present work identifies CYP46A1 as a major player in the regulation of prenylation and activity of sGTPases in neuronal cells. We show that CYP46A1 overexpression induces the activation of the mevalonate pathway, and thereby increases the pool of isoprenoids, as reflected by an increase in prenylation and activation of sGTPases. These results suggest that modulation of CYP46A1 expression can alter the content of prenylated proteins and their activity in neuronal cells, namely that of sGTPases. As mentioned above, these proteins are involved in several CNS pivotal processes ranging from endocytosis to synaptic modulation. Interestingly, Cyp $46 a 1$ null mice have decreased cognitive functions $[18,19]$ and, in contrast, transgenic mice overexpressing CYP46A1 possess an improvement of cognitive functions [20]. In both cases, these effects were suggested to be due to the inactivation or activation of the mevalonate pathway, respectively. Interestingly, the LTP deficiencies in the knockout mice lacking Cyp46al could not be restored by addition of cholesterol [18] which suggests that cholesterol levels are not directly implicated in cognitive changes elicited by modulation of CYP46A1 expression. In light of these studies and the present results, we put forward the hypothesis that CYP46A1 can influence high-order brain functions such as memory and learning, in part, through modulation of prenylation and activation status of sGTPases. This mechanism may also be part of the explanation for the cognitive improvement in the AD mice model overexpressing CYP46A1 [17]. Indeed, as above-mentioned sGTPases proteins are involved in the control axon growth, guidance and branching, dendritic spine formation and stabilization, growth cone motility and collapse and synapse formation [29-31], and consequently on memory formation, LTP induction and maintenance, and synaptic modulation [31, 33, 34]. We are currently investigation the full impact of CYP46A1-dependent sGTPases activation, namely in terms of neuronal development and function.

Interestingly, in contrast to the effect of CYP46A1 overexpression, incubation with $24 \mathrm{OHC}$ decreases membrane association of RhoA, while it increases the membrane abundance of the other sGTPases studied. LXR ligands have been previously 
Fig. 11 CYP46A1-dependent inhibition of the LXR pathway is a consequence of sGTPases prenylation. a qPCR analysis of ABCA1 and APOE mRNA levels in SH-SY5Y cells transfected with empty vector (Empty) or pFLAG-hCYP46A1 $(h C Y P)$ for $24 \mathrm{~h}$ and treated for further $24 \mathrm{~h}$ with $50 \mathrm{nM}$ GGTi-2133 or vehicle. $\mathbf{b}$ qPCR analysis of ABCA1 and APOE mRNA levels in SHSY5Y cells co-transfected with Empty or hCYP, and with $\mathrm{pEGFP}$ empty $(p N 1)$ or pEGFP-RhoA N19 dominant-negative vector (RhoAN19) for 48 h. Data is represented as mean values \pm SEM of at least three independent experiments and is expressed as fold change relative to control $\left({ }^{*} p<0.05, * * p<0.01\right)$

Fig. 12 CYP46A1

overexpression decreases LXR transcriptional activity. a LXREor LXRE mut-ABCA1 luciferase reporter plasmids were cotransfected with empty vector (Empty) or pFLAG-hCYP46A1 $(h C Y P)$ for 48 h. b LXRE-

ABCA1 luciferase reporter plasmid was co-transfected with empty vector (Empty) or pFLAGhCYP46A1 $(h C Y P)$ and with pEGFP empty or pEGFP-RhoA N19 (RhoAN19) dominantnegative vector for $48 \mathrm{~h}$. Normalized luciferase activities are expressed as mean values \pm SEM of duplicates for a minimum of three independent experiments $(* * * p<0.001)$
A
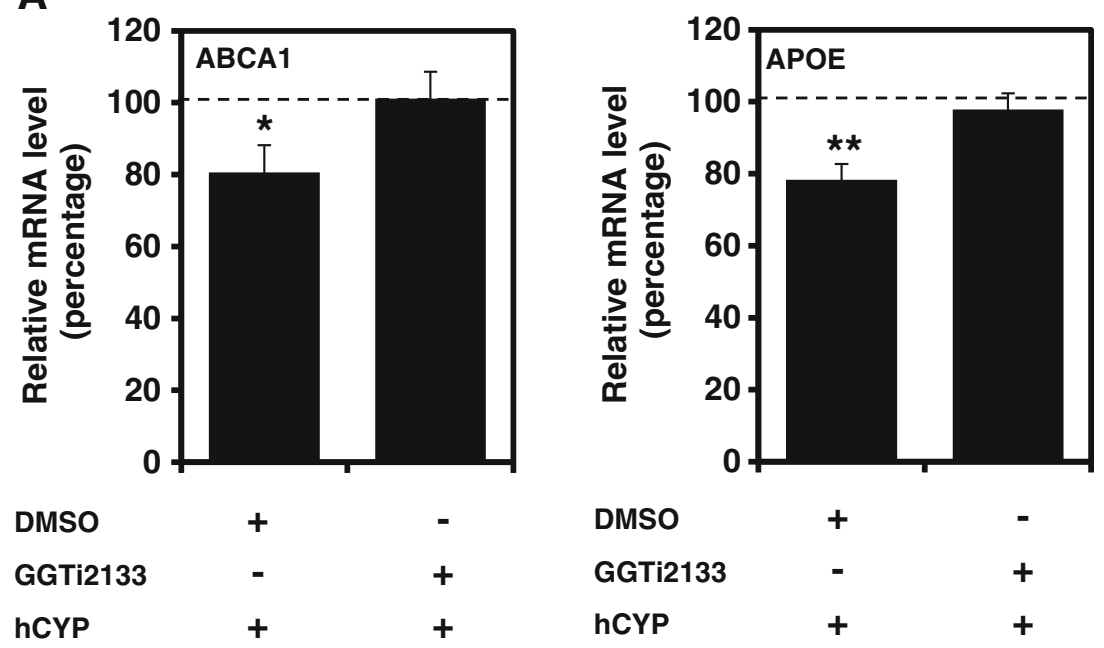

B
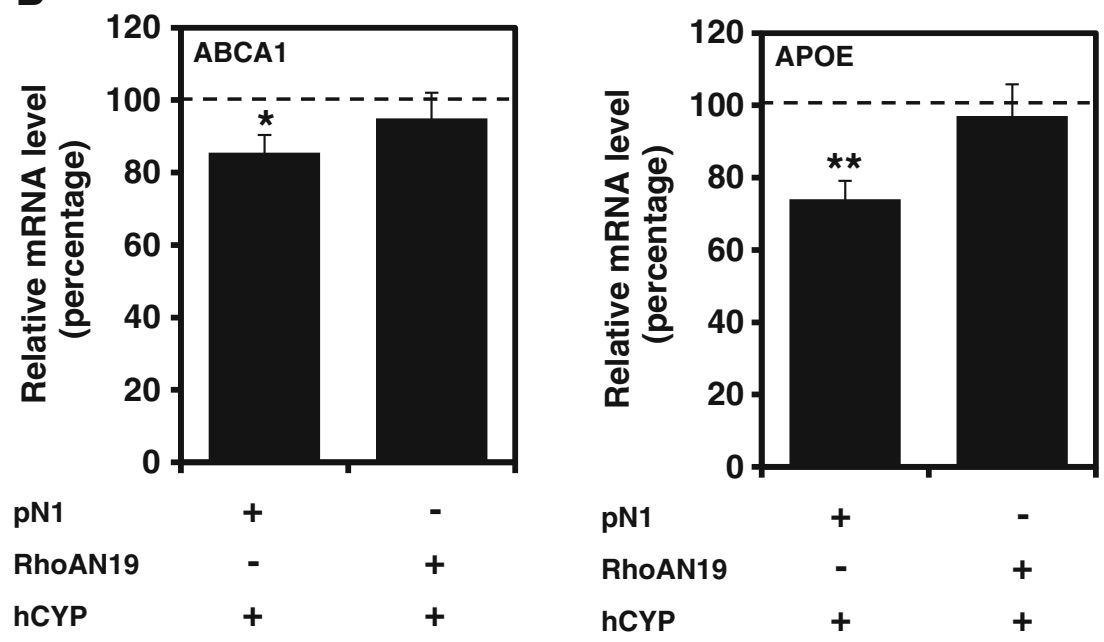

A

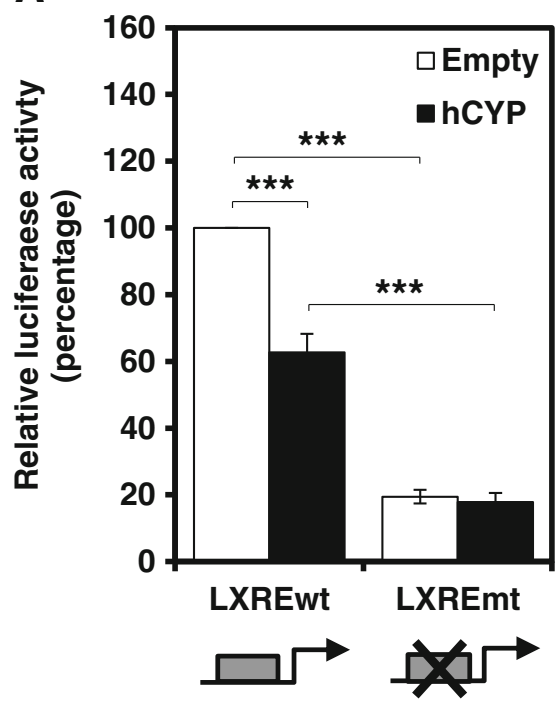

B

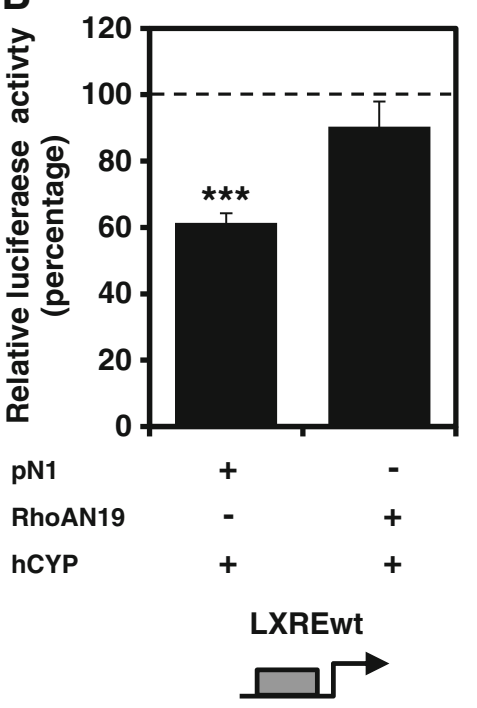


shown to have differential effects on the activation of Rho family members, namely by inhibiting RhoA and activating Cdc42 [50, 51]. Moreover, RhoA has been reported to inhibit LXR [45-49], suggesting integration between Rho-dependent functions and LXR activation. Our experiments on the effect of CYP46A1 overexpression on the LXR pathway show that, in contrast to the effect of added $24 \mathrm{OHC}$, increased levels of CYP46A1 reduced the expression of LXR target genes ABCA1 and APOE, which are critical for cholesterol efflux in neurons [52-56]. Interestingly, this decrease was abolished in the presence of a prenyltransferase inhibitor or by the co-transfection of a RhoA dominant-negative mutant. In agreement with the CYP46A1-dependent decrease in ABCA1 and APOE mRNA levels, we observed that the increase in CYP46A1 expression negatively affected the LXR transcriptional activity, and that this decrease was once again rescued by co-transfection of a RhoA dominant-negative mutant. These results strongly indicate that CYP46A1 overexpression can repress the LXR pathway in neurons through the activation of RhoA, in a prenylationdependent manner. It is tempting to suggest that the present data reflect a global mechanism of cellular response to cholesterol reduction by CYP46A1 in neurons. In order to avoid cholesterol depletion, the cells activate cholesterol synthesis in parallel with a down-regulation of the LXR target genes related to cholesterol efflux (ABCA1 and ApoE). Acute cholesterol depletion by cyclodextrin treatment results in altered membrane properties that can affect synaptic transmission in Purkinje cells and wildtype hippocampal neurons $[57,58]$. On the other hand, Sodero and coworkers have suggested that a sudden rise in excitatory neurotransmission activate CYP46A1-dependent mild cholesterol loss mechanisms to protect themselves from neuronal death [59]. Since CYP46A1 activity produces $24 \mathrm{OHC}$, one may speculate that the CYP46A1-sGTPases-LXR axis in neurons is an additional layer of the cell's cholesterol quality control, impairing cholesterol reduction to levels that may affect synaptic transmission. Interestingly, our results may also explain the previous in vivo reports that overexpression of CYP46A1 in mice does not lead to activation of the LXR pathway in spite of the high levels of the efficient LXR agonist $24 \mathrm{OHC}[16,17]$.

\begin{abstract}
Acknowledgments We deeply thank Dr. Peter Tontonoz (Howard Hughes Medical Institute, University of California, Los Angeles, USA) for kindly providing the LXRE- and LXRE mut-ABCA1 luciferase reporter plasmids and to Dr. Peter Jordan (Instituto Nacional de Saúde Doutor Ricardo Jorge, Lisbon, Portugal) for the plasmid encoding a dominant negative mutant of RhoA (pEGFP RhoA N19). This work was supported by FEDER (COMPETE Programme) and by national funds (E.R.) (FCT-Fundação para a Ciência e a Tecnologia - project PTDC/SAUNMC/110809/2009 and PhD grants SFRH/BD/41848/2007 to M.J.N. and SFRH/BD/78041/2011 to M.M.), and by the Swedish Science Council and Swedish Brain Power (I.B.)
\end{abstract}

Conflict of Interest The authors declare that they have no conflict of interest.

\section{References}

1. Fan QW, Yu W, Senda T, Yanagisawa K, Michikawa M (2001) Cholesterol-dependent modulation of tau phosphorylation in cultured neurons. J Neurochem 76(2):391-400. doi:10.1046/j.1471-4159. 2001.00063.x

2. Fan QW, Yu W, Gong JS, Zou K, Sawamura N, Senda T, Yanagisawa K, Michikawa M (2002) Cholesterol-dependent modulation of dendrite outgrowth and microtubule stability in cultured neurons. J Neurochem 80(1):178-190. doi:10.1046/j.0022-3042.2001.00686.x

3. Ko M, Zou K, Minagawa H, Yu W, Gong JS, Yanagisawa K, Michikawa M (2005) Cholesterol-mediated neurite outgrowth is differently regulated between cortical and hippocampal neurons. J Biol Chem 280(52):42759-42765. doi:10.1074/jbc.M509164200

4. Karten B, Vance DE, Campenot RB, Vance JE (2003) Trafficking of cholesterol from cell bodies to distal axons in Niemann Pick C1-deficient neurons. J Biol Chem 278(6):4168-4175. doi:10.1074/jbc.M205406200

5. Hayashi H, Campenot RB, Vance DE, Vance JE (2004) Glial lipoproteins stimulate axon growth of central nervous system neurons in compartmented cultures. J Biol Chem 279(14):14009-14015. doi:10. 1074/jbc.M313828200

6. Jia JY, Lamer S, Schumann M, Schmidt MR, Krause E, Haucke V (2006) Quantitative proteomics analysis of detergent-resistant membranes from chemical synapses: evidence for cholesterol as spatial organizer of synaptic vesicle cycling. Mol Cell Proteomics 5(11): 2060-2071. doi:10.1074/mcp.M600161-MCP200

7. Pfrieger FW (2003) Role of cholesterol in synapse formation and function. Biochim Biophys Acta 1610(2):271-280. doi:10.1016/ S0005-2736(03)00024-5

8. Lang T, Bruns D, Wenzel D, Riedel D, Holroyd P, Thiele C, Jahn R (2001) SNAREs are concentrated in cholesterol-dependent clusters that define docking and fusion sites for exocytosis. EMBO J 20(9): 2202-2213. doi:10.1093/emboj/20.9.2202

9. Suzuki S, Kiyosue K, Hazama S, Ogura A, Kashihara M, Hara T, Koshimizu H, Kojima M (2007) Brain-derived neurotrophic factor regulates cholesterol metabolism for synapse development. J Neurosci 27(24):6417-6427. doi:10.1523/JNEUROSCI.0690-07.2007

10. Hooff GP, Wood WG, Muller WE, Eckert GP (2010) Isoprenoids, small GTPases and Alzheimer's disease. Biochim Biophys Acta 1801(8):896-905. doi:10.1016/j.bbalip.2010.03.014

11. Bjorkhem I (2006) Crossing the barrier: oxysterols as cholesterol transporters and metabolic modulators in the brain. J Intern Med 260(6):493-508. doi:10.1111/j.1365-2796.2006.01725.x

12. Lund EG, Guileyardo JM, Russell DW (1999) cDNA cloning of cholesterol 24-hydroxylase, a mediator of cholesterol homeostasis in the brain. Proc Natl Acad Sci U S A 96(13):7238-7243. doi:10. 1073/pnas.96.13.7238

13. Lund EG, Xie C, Kotti T, Turley SD, Dietschy JM, Russell DW (2003) Knockout of the cholesterol 24-hydroxylase gene in mice reveals a brain-specific mechanism of cholesterol turnover. J Biol Chem 278(25):22980-22988. doi:10.1074/jbc.M303415200

14. Lehmann JM, Kliewer SA, Moore LB, Smith-Oliver TA, Oliver BB, Su JL, Sundseth SS, Winegar DA, Blanchard DE, Spencer TA, Willson TM (1997) Activation of the nuclear receptor LXR by oxysterols defines a new hormone response pathway. J Biol Chem 272(6):3137-3140. doi:10.1074/jbc.272.6.3137

15. Abildayeva K, Jansen PJ, Hirsch-Reinshagen V, Bloks VW, Bakker AH, Ramaekers FC, de Vente J, Groen AK, Wellington CL, Kuipers F, Mulder M (2006) 24(S)-Hydroxycholesterol participates in a liver $\mathrm{X}$ receptor-controlled pathway in astrocytes that regulates apolipoprotein E-mediated cholesterol efflux. J Biol Chem 281(18):12799 12808. doi:10.1074/jbc.M601019200

16. Shafaati M, Olin M, Bavner A, Pettersson H, Rozell B, Meaney S, Parini P, Bjorkhem I (2011) Enhanced production of 24Shydroxycholesterol is not sufficient to drive liver $\mathrm{X}$ receptor target 
genes in vivo. J Intern Med 270(4):377-387. doi:10.1111/j.13652796.2011.02389.x

17. Hudry E, Van Dam D, Kulik W, De Deyn PP, Stet FS, Ahouansou O, Benraiss A, Delacourte A, Bougneres P, Aubourg P, Cartier N (2010) Adeno-associated virus gene therapy with cholesterol 24hydroxylase reduces the amyloid pathology before or after the onset of amyloid plaques in mouse models of Alzheimer's disease. Mol Ther 18(1):44-53. doi:10.1038/mt.2009.175

18. Kotti TJ, Ramirez DM, Pfeiffer BE, Huber KM, Russell DW (2006) Brain cholesterol turnover required for geranylgeraniol production and learning in mice. Proc Natl Acad Sci U S A 103(10):3869-3874. doi:10.1073/pnas.0600316103

19. Kotti T, Head DD, McKenna CE, Russell DW (2008) Biphasic requirement for geranylgeraniol in hippocampal long-term potentiation. Proc Natl Acad Sci U S A 105(32):11394-11399. doi:10.1073/ pnas.0805556105

20. Maioli S, Bavner A, Ali Z, Heverin M, Ismail MA, Puerta E, Olin M, Saeed A, Shafaati M, Parini P, Cedazo-Minguez A, Bjorkhem I (2013) Is it possible to improve memory function by upregulation of the cholesterol 24S-hydroxylase (CYP46A1) in the brain? PLoS ONE 8(7):e68534. doi:10.1371/journal.pone.0068534

21. Takai Y, Sasaki T, Matozaki T (2001) Small GTP-binding proteins. Physiol Rev 81(1):153-208

22. Wennerberg K, Rossman KL, Der CJ (2005) The Ras superfamily at a glance. J Cell Sci 118(Pt 5):843-846. doi:10.1242/jcs.01660

23. Konstantinopoulos PA, Karamouzis MV, Papavassiliou AG (2007) Post-translational modifications and regulation of the RAS superfamily of GTPases as anticancer targets. Nat Rev Drug Discov 6(7):541555. doi:10.1038/nrd2221

24. Rowinsky EK, Windle JJ, Von Hoff DD (1999) Ras protein farnesyltransferase: a strategic target for anticancer therapeutic development. J Clin Oncol 17(11):3631-3652

25. Roberts PJ, Mitin N, Keller PJ, Chenette EJ, Madigan JP, Currin RO, Cox AD, Wilson O, Kirschmeier P, Der CJ (2008) Rho Family GTPase modification and dependence on CAAX motif-signaled posttranslational modification. J Biol Chem 283(37):25150-25163. doi:10.1074/jbc.M800882200

26. Leung KF, Baron R, Seabra MC (2006) Thematic review series: lipid posttranslational modifications. geranylgeranylation of Rab GTPases. J Lipid Res 47(3):467-475. doi:10.1194/jlr.R500017-JLR200

27. Wilson AL, Erdman RA, Castellano F, Maltese WA (1998) Prenylation of Rab8 GTPase by type I and type II geranylgeranyl transferases. Biochem J 333(Pt 3):497-504

28. Cherfils J, Zeghouf M (2013) Regulation of small GTPases by GEFs, GAPs, and GDIs. Physiol Rev 93(1):269-309. doi:10.1152/physrev. 00003.2012

29. Govek EE, Hatten ME, Van Aelst L (2011) The role of Rho GTPase proteins in CNS neuronal migration. Dev Neurobiol 71(6):528-553. doi:10.1002/dneu.20850

30. Govek EE, Newey SE, Van Aelst L (2005) The role of the Rho GTPases in neuronal development. Genes Dev 19(1):1-49. doi:10. 1101/gad.1256405

31. Hall A, Lalli G (2010) Rho and Ras GTPases in axon growth, guidance, and branching. Cold Spring Harb Perspect Biol 2(2): a001818. doi:10.1101/cshperspect.a001818

32. Thurnherr T, Benninger Y, Wu X, Chrostek A, Krause SM, Nave KA, Franklin RJ, Brakebusch C, Suter U, Relvas JB (2006) Cdc42 and Rac1 signaling are both required for and act synergistically in the correct formation of myelin sheaths in the CNS. J Neurosci 26(40): 10110-10119. doi:10.1523/JNEUROSCI.2158-06.2006

33. Kim JH, Lee HK, Takamiya K, Huganir RL (2003) The role of synaptic GTPase-activating protein in neuronal development and synaptic plasticity. J Neurosci 23(4):1119-1124

34. Ye X, Carew TJ (2010) Small G protein signaling in neuronal plasticity and memory formation: the specific role of ras family proteins. Neuron 68(3):340-361. doi:10.1016/j.neuron.2010.09.013
35. Ng EL, Tang BL (2008) Rab GTPases and their roles in brain neurons and glia. Brain Res Rev 58(1):236-246. doi:10.1016/j.brainresrev. 2008.04.006

36. Agola J, Jim P, Ward H, Basuray S, Wandinger-Ness A (2011) Rab GTPases as regulators of endocytosis, targets of disease and therapeutic opportunities. Clin Genet 80(4):305-318. doi:10.1111/j.13990004.2011.01724.x

37. Aizman E, Mor A, Levy A, George J, Kloog Y (2012) Ras inhibition by FTS attenuates brain tumor growth in mice by direct antitumor activity and enhanced reactivity of cytotoxic lymphocytes. Oncotarget 3(2): 144-157

38. Khalil BD, El-Sibai M (2012) Rho GTPases in primary brain tumor malignancy and invasion. J Neuro Oncol 108(3):333-339. doi:10. 1007/s11060-012-0866-8

39. Kubo T, Yamaguchi A, Iwata N, Yamashita T (2008) The therapeutic effects of Rho-ROCK inhibitors on CNS disorders. Ther Clin Risk Manag 4(3):605-615. doi:10.2147/TCRM.S2907

40. Seabra MC, Brown MS, Goldstein JL (1993) Retinal degeneration in choroideremia: deficiency of rab geranylgeranyl transferase. Science 259(5093):377-381. doi:10.1126/science.8380507

41. Walters CE, Pryce G, Hankey DJ, Sebti SM, Hamilton AD, Baker D, Greenwood J, Adamson P (2002) Inhibition of Rho GTPases with protein prenyltransferase inhibitors prevents leukocyte recruitment to the central nervous system and attenuates clinical signs of disease in an animal model of multiple sclerosis. J Immunol 168(8):4087-4094. doi:10.4049/jimmunol.168.8.4087

42. Tonges L, Frank T, Tatenhorst L, Saal KA, Koch JC, Szego EM, Bahr M, Weishaupt JH, Lingor P (2012) Inhibition of rho kinase enhances survival of dopaminergic neurons and attenuates axonal loss in a mouse model of Parkinson's disease. Brain 135(Pt 11):3355-3370. doi:10.1093/brain/aws254

43. Milagre I, Nunes MJ, Gama MJ, Silva RF, Pascussi JM, Lechner MC, Rodrigues E (2008) Transcriptional regulation of the human CYP46A1 brain-specific expression by $\mathrm{Sp}$ transcription factors. J Neurochem 106(2):835-849. doi:10.1111/j.1471-4159.2008.05442.x

44. Brewer GJ, Torricelli JR, Evege EK, Price PJ (1993) Optimized survival of hippocampal neurons in B27-supplemented neurobasal, a new serum-free medium combination. J Neurosci Res 35(5):567576. doi:10.1002/jnr.490350513

45. Qiu G, Hill JS (2008) Atorvastatin inhibits ABCA1 expression and cholesterol efflux in THP-1 macrophages by an LXR-dependent pathway. J Cardiovasc Pharmacol 51(4):388-395. doi:10.1097/FJC. 0b013e318167141f

46. Gan X, Kaplan R, Menke JG, MacNaul K, Chen Y, Sparrow CP, Zhou G, Wright SD, Cai TQ (2001) Dual mechanisms of ABCA1 regulation by geranylgeranyl pyrophosphate. J Biol Chem 276(52): 48702-48708. doi:10.1074/jbc.M109402200

47. Okuhira K, Fitzgerald ML, Tamehiro N, Ohoka N, Suzuki K, Sawada J, Naito M, Nishimaki-Mogami T (2010) Binding of PDZ-RhoGEF to ATP-binding cassette transporter A1 (ABCA1) induces cholesterol efflux through RhoA activation and prevention of transporter degradation. J Biol Chem 285(21):16369-16377. doi:10.1074/jbc.M109.061424

48. Argmann CA, Edwards JY, Sawyez CG, O'Neil CH, Hegele RA, Pickering JG, Huff MW (2005) Regulation of macrophage cholesterol efflux through hydroxymethylglutaryl-CoA reductase inhibition: a role for RhoA in ABCA1-mediated cholesterol efflux. J Biol Chem 280(23):22212-22221. doi:10.1074/jbc.M502761200

49. Maejima T, Yamazaki H, Aoki T, Tamaki T, Sato F, Kitahara M, Saito Y (2004) Effect of pitavastatin on apolipoprotein A-I production in HepG2 cell. Biochem Biophys Res Commun 324(2):835-839. doi: 10.1016/j.bbrc.2004.09.122

50. ElAli A, Hermann DM (2012) Liver X receptor activation enhances blood-brain barrier integrity in the ischemic brain and increases the abundance of ATP-binding cassette transporters ABCB1 and ABCC1 on brain capillary cells. Brain Pathol 22(2):175-187. doi:10.1111/j. 1750-3639.2011.00517.x 
51. Smoak K, Madenspacher J, Jeyaseelan S, Williams B, Dixon D, Poch KR, Nick JA, Worthen GS, Fessler MB (2008) Effects of liver X receptor agonist treatment on pulmonary inflammation and host defense. J Immunol 180(5):3305-3312. doi:10.4049/jimmunol.180.5.3305

52. Xu PT, Gilbert JR, Qiu HL, Rothrock-Christian T, Settles DL, Roses AD, Schmechel DE (1998) Regionally specific neuronal expression of human APOE gene in transgenic mice. Neurosci Lett 246(2):65-68. doi:10.1016/S0304-3940(98)00247-X

53. Dekroon RM, Armati PJ (2001) Synthesis and processing of apolipoprotein E in human brain cultures. Glia 33(4):298-305

54. Metzger RE, LaDu MJ, Pan JB, Getz GS, Frail DE, Falduto MT (1996) Neurons of the human frontal cortex display apolipoprotein E immunoreactivity: implications for Alzheimer's disease. J Neuropathol Exp Neurol 55(3):372-380

55. Bao F, Arai H, Matsushita S, Higuchi S, Sasaki H (1996) Expression of apolipoprotein $\mathrm{E}$ in normal and diverse neurodegenerative disease brain. Neuroreport 7(11):1733-1739
56. Harris FM, Tesseur I, Brecht WJ, Xu Q, Mullendorff K, Chang S, Wyss-Coray T, Mahley RW, Huang Y (2004) Astroglial regulation of apolipoprotein $\mathrm{E}$ expression in neuronal cells. Implications for Alzheimer's disease. J Biol Chem 279(5):3862-3868. doi:10.1074/ jbc.M309475200

57. Wasser CR, Ertunc M, Liu X, Kavalali ET (2007) Cholesteroldependent balance between evoked and spontaneous synaptic vesicle recycling. J Physiol 579(Pt 2):413-429. doi:10.1113/jphysiol.2006. 123133

58. Smith AJ, Sugita S, Charlton MP (2010) Cholesterol-dependent kinase activity regulates transmitter release from cerebellar synapses. J Neurosci 30(17):6116-6121. doi:10.1523/JNEUROSCI.0170-10. 2010

59. Sodero AO, Vriens J, Ghosh D, Stegner D, Brachet A, Pallotto M, Sassoe-Pognetto M, Brouwers JF, Helms JB, Nieswandt B, Voets T, Dotti CG (2012) Cholesterol loss during glutamate-mediated excitotoxicity. EMBO J 31(7):1764-1773. doi:10.1038/emboj.2012.31 